[6] Martindale J. The impact of delay in diagnosing ankylosing spondylitis/axial SpA. . Rheumatology. 2014;53.

[7] Yi EA-O, Ahuja A, Rajput T, George AT, Park Y. Clinical, Economic, and Humanistic Burden Associated With Delayed Diagnosis of Axial Spondyloarthritis: A Systematic Review. Rheumatol Ther 2020(2198-6576 (Print)):65-87.

Disclosure of Interests: Kate Lapane: None declared, Catherine Dubé Grant/ research support from: Novartis, as personnel on such studies, Katarina Ferrucci: None declared, Sara Khan: None declared, Kristine A. Kuhn Consultant of: UCB, Eli Lilly, Novartis, Grant/research support from: Pfizer, Alexis Ogdie Consultant of: Abbvie, Amgen, BMS, Celgene, Corrona, Gilead, Janssen, Lilly, Novartis, Pfizer, UCB, Grant/research support from: Pfizer to Penn, Novartis to Penn, Amgen to Forward/NDB, Esther Yi Employee of: Novartis Pharmaceuticals, Jonathan Kay Consultant of: AbbVie, Inc.; Boehringer Ingelheim $\mathrm{GmbH}$; Celltrion Healthcare Co. Ltd.; Jubilant Radiopharma; Merck \& Co.,Inc.; Pfizer Inc.; Samsung Bioepis; Sandoz Inc.; Scipher Medicine; UCB, Inc., Grant/research support from: (paid to UMass Medical School) Gilead Sciences Inc.; Novartis Pharmaceuticals Corp.; Pfizer Inc., Shao-Hsien Liu Grant/research support from: Novartis DOI: 10.1136/annrheumdis-2021-eular.2749

\section{AB0893-HPR TREATMENT SATISFACTION, EXPECTATIONS, PATIENT PREFERENCES, AND CHARACTERISTICS IN PATIENTS WITH RHEUMATOID ARTHRITIS (RA): TURKISH COHORT RESULTS OF THE SENSE STUDY}

U. Kalyoncu' 1 , A. Kucuk ${ }^{2}$, G. Sargin ${ }^{3}$, F. Ozdener ${ }^{4}$, S. Yolbasş, B. Yurttas ${ }^{6}$, S. Turan ${ }^{7}$, G. Kimyon ${ }^{8}$, A. Sahin ${ }^{9}$, S. Yilmaz ${ }^{10}$, R. Mercan ${ }^{11}$, H. Emmungil ${ }^{6}$, M. Çınar ${ }^{10}$, I. Sezer ${ }^{12}$, T. Kașifoğlu ${ }^{13}$, F. Cosan ${ }^{4}$, T. Senturk ${ }^{8}$, N. Inanc ${ }^{14} .{ }^{1}$ Hacettepe University - Faculty of Medicine, Department of Internal Medicine, Division of Rheumatology, Ankara, Turkey; ${ }^{2}$ Necmettin Erbakan University - Meram Faculty of Medicine, Department of Internal Medicine, Division of Rheumatology, Kony, Turkey; ${ }^{3}$ Aydin Adnan Menderes University - Faculty of Medicine, Department of Internal Medicine, Division of Rheumatology, Aydin, Turkey; ${ }^{4}$ Bahcesehir University - Faculty of Medicine, Department of Pharmacology, Istanbul, Turkey; ${ }^{5}$ Inonu University - Turgut Ozal Medical Center Training and Research Hospital, Department of Internal Medicine, Division of Rheumatology, Malatya, Turkey; ${ }^{6}$ Istanbul University Cerrahpasa - Cerrahpasa Faculty of Medicine, Department of Internal Medicine, Division of Rheumatology, Istanbul, Turkey; ${ }^{7}$ Trakya University - Faculty of Medicine, Department of Internal Medicine, Division of Rheumatology, Edirne, Turkey; ${ }^{8}$ Mustafa Kemal University - Faculty of Medicine, Department of Internal Medicine, Division of Rheumatology, Hatay, Turkey; ${ }^{9}$ Sivas Cumhuriyet University - Faculty of Medicine, Department of Internal Medicine, Division of Rheumatology, Sivas, Turkey; ${ }^{10}$ University of Health Sciences Turkey - Gulhane Faculty of Medicine, Department of Internal Medicine, Division of Rheumatology, Ankara, Turkey; ${ }^{11}$ Namik Kemal University - Faculty of Medicine, Department of Internal Medicine, Division of Rheumatology, Tekirdag, Turkey; ${ }^{12}$ Akdeniz University - Faculty of Medicine, Department of Internal Medicine, Division of Rheumatology, Antalya, Turkey; ${ }^{13}$ Eskisehir Osmangazi University - Faculty of Medicine, Department of Internal Medicine, Division of Rheumatology, Eskisehir, Turkey; ${ }^{14}$ Marmara University - School of Medicine, Department of Internal Medicine, Division of Rheumatology, Istanbul, Turkey

Background: Suboptimal control of RA may lead to severe and progressive articular damage, loss of function, and deterioration of the quality of life (QoL). Objectives: To assess treatment satisfaction, sociodemographic, clinical, health care resource utilization, and QoL characteristics of patients with sub-optimally controlled RA and treated with conventional synthetic and/or biologic DMARDs. Methods: This study was an international, multicenter, cross-sectional, non-interventional study. Adult RA patients with moderate to severe disease activity (DAS28>3.2) were enrolled. Patient satisfaction was evaluated with Treatment Satisfaction Questionnaire for Medication (TSQM, version 1.4) with a scale ranging from 0 (indicating poor satisfaction) to 100 (indicating perfect satisfaction). Patients were questioned regarding treatment adherence, patient preferences, and expectations. Workability was evaluated using Work Productivity and Activity Impairment Questionnaire-Rheumatoid Arthritis (WPAI-RA, version 2.0). Short Form 36 (V2) survey were performed to all patients.

Results: One hundred sixty-four patients were included in the study and most $(78.0 \%)$ were female. The median age was 57.0 years, ranging between 22.0 and 84.0 years. Half of the patients $(50.6 \%)$ were primary school graduates and $6.1 \%$ were unemployed due to RA and seeking work. Median time since RA diagnosis was 8.0 years and mean $( \pm \mathrm{SD})$ DAS28-CRP score was $4.8( \pm 1.0)$. Mean total activity impairment was $54.9 \%( \pm 27.4)$. In the past 3 months from enrollment, the mean number of healthcare professional and emergency room visits were $1.8( \pm 1.1)$ and $1.8( \pm 1.3)$, respectively. Mean number and length of hospitalizations in the previous 3 months were $1.1( \pm 0.3)$ times and $8.3( \pm 7.2)$ days, respectively. Mean TSQM scores were $53.5( \pm 21.4)$ for effectiveness, 86.0 $( \pm 26.7)$ for side effects, $67.8( \pm 16.5)$ for convenience, and $57.7( \pm 22.0)$ for global satisfaction. The leading expectation was 'lasting relief of RA symptoms' (mean score: 5.8). Preferred time until the effect of onset was 'up to 1 week' for $76.2 \%$ of the patients. Most of the patients (57.9\%) preferred oral administrations and the most preferred frequency of administration was 'once per day' (46.3\%). Mean physical and mental component summary scores for Short Form 36 (V2) survey were $37.9( \pm 8.3)$ and $40.1( \pm 10.7)$

Conclusion: Two-thirds of the patients with RA who have suboptimal responses are not satisfied with their treatments. Moreover, oral and once-daily treatment approaches stand out in patient preferences. Finally, suboptimal control leads to deterioration in clinical characteristics, workability, and QoL of patients with RA. Acknowledgements: The design, study conduct, and financial support for the study were provided by AbbVie. AbbVie participated in the interpretation of data, review, and approval of the publication. All authors have received research funding for this study. The authors wish to thank B. Murat Ozdemir of Monitor CRO for medical editing and reviewing services of this manuscript. AbbVie provided funding to Monitor $\mathrm{CRO}$ for this work.

Disclosure of Interests: Umut Kalyoncu Speakers bureau: AbbVie, Pfizer, UCB Novartis, and Janssen, Consultant of: AbbVie, Pfizer, UCB, Novartis, and Lilly, Grant/research support from: AbbVie, Pfizer, and Janssen, Adem Kucuk Speakers bureau: AbbVie, Gokhan Sargin: None declared, Fatih Ozdener Speakers bureau: UCB, Nutricia Advanced Medical Nutrition, Grant/research support from: Nutricia Advanced Medical Nutrition, Servet Yolbas Speakers bureau: AbbVie, UCB, Pfizer, and MSD, Berna Yurttas: None declared, Sezin Turan: None declared, Gezmiş Kimyon Speakers bureau: AbbVie, Amgen, Pfizer, Novartis, UCB, MSD, Johnson and Johnson, and Celltrion, Consultant of: Amgen, and Pfizer, ALI SAHIN Speakers bureau: Roche, Pfizer, and AbbVie, Consultant of Roche and Pfizer, Sedat Yilmaz Speakers bureau: UCB, Pfizer, AbbVie, MSD, Novartis, and Celltrion, Consultant of: Pfizer and Novartis, Rıdvan Mercan Speakers bureau: AbbVie, Novartis, MSD, Pfizer, UCB, Roche, Amgen, and Celltrion, Consultant of: Novartis, MSD, Pfizer, and Celltrion, Hakan Emmungil Speakers bureau: AbbVie, Pfizer, Novartis, and MSD, Muhammet Çınar Speakers bureau: AbbVie, Pfizer, Celltrion, UCB, Amgen, Novartis, and MSD, Grant research support from: AbbVie, Pfizer, Celltrion, UCB, Amgen, Novartis, and MSD, İlhan Sezer Speakers bureau: AbbVie, Pfizer, MSD, Novartis, Celltrion, UCB, Amgen, and Abdi Ibrahim, Consultant of: AbbVie, Pfizer, MSD, Novartis, Celltrion, UCB, Amgen, and Abdi Ibrahim, Grant/research support from: AbbVie, Pfizer, MSD, Novartis, Celltrion, UCB, Amgen, and Abdi Ibrahim, Timuçin Kaşifoğlu Speakers bureau: AbbVie, Amgen, Roche, MSD, Novartis, Pfizer, and UCB, Consultant of: AbbVie, Amgen, Roche, MSD, Novartis, Pfizer, and UCB, Fulya Cosan Speakers bureau: AbbVie, Pfizer, Novartis, UCB, and MSD, Taskin Senturk: None declared, Nevsun Inanc Speakers bureau: AbbVie, UCB, Novartis, Pfizer, Roche, Lilly and MSD, Consultant of: Roche and Pfizer, Grant/research support from: Roche and Pfizer

DOI: 10.1136/annrheumdis-2021-eular.2846

\section{AB0894-HPR THE JOURNEY OF PATIENTS WITH RHEUMATOID ARTHRITIS}

M. Fusama ${ }^{1}$, S. Oliver ${ }^{2}$, H. Nakahara ${ }^{3}$, Y. Van Eijk-Hustings ${ }^{4}$, Y. Kuroe ${ }^{5}$. ${ }^{1}$ Takarazuka University, School of Nursing, Osaka, Japan; ${ }^{2}$ Susan Oliver Associates, Nurse Consultant, Barnstaple, Devon., United Kingdom; ${ }^{3}$ Osaka Yukioka College of Health Science, Department of Physical Therapy, Ibaragi, Japan; ${ }^{4}$ Clinical Epidemiology and Medical Technology Assessment (KEMTA), Department of Patient\&Care, Amsterdam, Netherlands: ${ }^{5}$ Gifu College of Nursing, School of Nursing, hashima, Japan

Background: The course of rheumatoid arthritis (RA) differs from patient to patient, and each patient has a unique story. The disease condition affects psychological and social aspects, greatly affecting the quality of life. The disease course is unpredictable, and each patient's story can be seen as a lifelong journey, full of ups and downs. Therefore, it is crucial to know what kind of support is required during the course of their life.

Objectives: The aim of this study is to examine the life story of patients with RA and clarify a common situation in their stories in order to consider what kind of support is needed.

Methods: This is a qualitative study using life story interview for patients with RA in Japan. Interview included disease history, patients' behaviors, effects on daily life, the patients' perspectives regarding psychological considerations and useful support. Data were analyzed using content analysis This study was approved by the ethics committee and informed consent was obtained.

Results: Eight patients participated in this study. They were all females and the average age was 57 years old. As a result of the categorization, we extracted the following eight situations: (1) Emergence of symptom; patients thought joint pain would go away, however, the symptom did not improve and began to affect their daily life and work, (2) Choose a hospital to visit; pain and anxiety have continued and decided to visit a hospital, (3) Encounter with their doctors; patients expected their doctor to relieve their pain, while they were afraid of being told that they were suffering from a serious disease. (4) Diagnosis of RA; patients were 
shocked when diagnosed and anxious about what would happen and wondered why they had such a disease, (5) Choice of treatment; patients were afraid of the side effects. They wanted to make a decision discussing with their doctor, but they could not understand the explanation about drugs well and, therefore, followed the doctor's opinion. (6) Change of treatment; a biological agent was often recommended. Patients were also worried about side effects and the financial burden. (7) Remission or stable phase; they felt better mentally too, however, they often felt anxiety about disease flare, side effect of drugs and financial burden, and (8) Flare and remission; patients felt shocked and disappointed when RA flared, and then, they noticed that patients with RA had alternating periods of relapse and remission and they had to live with RA.

These interviews revealed repeated worsening and improvement of symptoms and many similar repeated psychological reactions such as anxiety, shock, denial, conflict, acceptance, giving up and relief. To cope with these fluctuating disease and mental conditions, patients were supported by educational and psychological assistance, timely consultations, social life help from nurses and support from their family. The patients considered a trusting relationship with their doctors is necessary. The patients had also realized through their experience the importance of enhancing their own abilities, such as decision-making, prevention of infections and self-management skills. Moreover, they noticed that it is important to have their own goals including hobbies and work.

Conclusion: This study elucidated the common behaviors of patients with RA, the impact of RA on their psychological state and daily and social life, and the required support. The psychological condition and daily and social life also had a great influence on medical behavior. Therefore, psychosocial support and establishment of trust between healthcare professionals and patients are crucial. In addition, improving patients' self-management skills including self-efficacy and empowerment is also necessary. As patients with RA often feel anxious in various situations and expect nurses' support, nurses should listen to patients, pay attention to their concerns and anxieties, and show a solution-oriented attitude. In order for patients to feel at ease in their Patient Journey, nurses should sail with them while maintaining a patient-centered perspective.

Disclosure of Interests: None declared

DOI: 10.1136/annrheumdis-2021-eular.3029

\section{AB0895-HPR A MODERATED MEDIATION ANALYSIS FOR POOR ORAL HEALTH-RELATED QUALITY OF LIFE IN PATIENTS WITH BEHÇET'S DISEASE}

E. N. Çakır ${ }^{1}$, Y. Yenisoy ${ }^{1}$, A. Kapusuz ${ }^{1}$, K. Abacar ${ }^{2}$, F. Alibaz-Oner ${ }^{2}$, M. Yay $^{3}$, Ü. Karaçaylı ${ }^{4}$, N. Inanc ${ }^{2}$, T. Ergun ${ }^{5}, \underline{H}$. Direskeneli ${ }^{2}$, G. Mumcu ${ }^{6} .{ }^{1}$ Marmara University, Institute of Health Sciences, Istanbul, Turkey; ${ }^{2}$ Marmara University, Division of Rheumatology, Istanbul, Turkey; ${ }^{3}$ Mimar Sinan Fine Arts University, Department of Statistics, Istanbul, Turkey; ${ }^{4}$ Health Sciences University, Department of Oral and Dental Surgery, Ankara, Turkey; ${ }^{5}$ Marmara University, Department of Dermatology, Istanbul, Turkey; ${ }^{6}$ Marmara University, Department of Health Management, Istanbul, Turkey

Background: Since oral ulcer is a common clinical manifestation, oral health-related quality of life (OHRQoL) is affected by the presence of oral ulcer poorly in patients with Behcet's disease (BD).

Objectives: The aim of the study was to examine associated factors for poor OHRQoL status to improve treatment outcomes in patients with $\mathrm{BD}$.

Methods: In this retrospective study, 339 BD patients (F/M: 179/160, mean age: $36,13 \pm 9,81$ years) included. Data were collected by a structured questionnaire regarding treatment expectation, Oral Health Impact Profile-14 (OHIP-14) questionnaire for OHRQoL, oral ulcer activity, and disease severity score. Treatment expectation was coded by a 5-point Likert type scale (1: symptoms were completely cured vs 5: symptoms were worsened). OHIP-14 score was between " 0 point (the best score)" and "56 points (the worst score)." The disease severity score was calculated according to the organ involvement. Then, patients were categorised as mucocutaneous involvement $(n=181)$ and severe organ involvement $(n=158)$. After preliminary analysis, a Moderated Mediation analysis was carried out.

Results: Oral ulcer activity was seen in $63,4 \%$ of the group $(n=215)$. OHIP-14 score $(22,05 \pm 16,47)$ was correlated with Treatment expectations $(2,35 \pm 0,98)$ ( $r: 0,36 \mathrm{p}=0.000$ ) in the group. Poor scores of OHIP-14 and Treatment expectations were found in patients with active oral ulcers (mucocutaneous involvement: $27,56 \pm 14,55 ; 2,68 \pm 0,87$, vs severe organ involvement: $28,51 \pm 17,25 ; 2,43 \pm 0,99$ ) compared to those of inactive patients (mucocutaneous involvement: $13,38 \pm 12,23$; $1,81 \pm 0,73$ vs severe organ involvement: $8,79 \pm 10,19 ; 1,85 \pm 1,02)(p=0.000$ for all). Patients with active oral ulcers were younger $(35,09 \pm 9,52)$ than the others $(39,57 \pm 10,06)$ in the mucocutaneous involvement group $(p=0.0011)$ whereas a similar relation was not seen in the severe organ involvement $(p=0.233)$.

In the moderated mediation analysis, it was found that OHIP-14 score was increased by the presence of oral ulcer in the direct path $(p=0.0000)$ and the negative Expectation of the treatment as a first mediator $(p=0.0001)$ in the indirect path. Oral ulcer activity was associated with younger patients $(p=0.0039)$. This effect was seen especially in patients with mucocutaneous involvement that had a moderator effect $(p=0.0040)$. In addition, age was found to be a second mediator for the poor OHIP-14 score $(p=0.0053)$. Mediators and the moderator were found to effective for OHIP-14 score a bootstrap analysis with 5000 replications. Conclusion: OHRQoL was affected by oral ulcer activity and poor treatment expectations. Age was also found to be another critical factor for OHRQoL.

Disclosure of Interests: None declared

DOI: 10.1136/annrheumdis-2021-eular.3043

\section{AB0896-HPR THE EVALUATION OF TYPE D PERSONALITY AND SELF-ESTEEM IN PATIENTS WITH FIBROMYALGIA}

N. Gokcen ${ }^{1}$, I. Coskun Benlidayi ${ }^{2}$, L. Tamam ${ }^{3}$, M. E. Demirkol ${ }^{3}$, C. Yesiloglu ${ }^{3}$, R. Guzel ${ }^{2}{ }^{1}$ Cukurova University Faculty of Medicine, Department of Physical Medicine and Rehabilitation, Division of Rheumatology, Adana, Turkey; ${ }^{2}$ Cukurova University Faculty of Medicine, Department of Physical Medicine and Rehabilitation, Adana, Turkey; ${ }^{3}$ Cukurova University Faculty of Medicine, Department of Psychiatry, Adana, Turkey

Background: Fibromyalgia (FM) is a condition characterized by chronic widespread pain, fatigue, sleep disturbances. Etiopathogenesis remains unclear; however, growing data regarding the effect of psychosocial factors on disease etiopathogenesis have drawn attention. Psychosocial elements such as type D personality and low level of self-esteem might increase disease burden (1). Accordingly, many researchers so far, have examined psychological parameters in FM and a limited number of studies focused on the personality type among patients with FM (2-5). Objectives: The current study aimed to investigate type $D$ personality and self-esteem in patients with FM.

Methods: Female patients with fibromyalgia and age-matched healthy controls were enrolled in this cross-sectional study. Type D personality was evaluated by using the type D scale (DS-14). The Rosenberg self-esteem scale (RSES) was used to assess self-esteem and psychosomatic symptoms. Psychological status was evaluated by the Beck Depression and Beck Anxiety Inventories. Fibromyalgia Impact Questionnaire (FIQ) was performed to assess functional impairment and health status in patients with FM. The potential confounders of type D personality were evaluated by binary logistic regression analysis.

Results: Seventy patients with FM and 60 controls were included. Type D personality was observed in $58.6 \%$ of the patients and in $21.7 \%$ of the control group $(p<0.001)$. When compared to patients with non-type $D$ personality, those with type $D$ personality revealed lower self-esteem and poorer health status $(p<0.05$ for both), higher anxiety and depression scores ( $p<0.001$ for both). According to binary logistic regression analysis, depression $(\beta=1.178, \mathrm{Cl} 95 \% 1.055-1.316$ $p=0.004)$ and lower education level $(\beta=0.818, C l 95 \% 0.682-0.982, p=0.031)$ were significantly related to type D personality in FM (Table 1).

Conclusion: Type D personality is more common in female patients with FM when compared to healthy women. Patients with type D personality have lower level of self-esteem when compared to those with non-type D personality. Depression and lower education level are potential confounders of type D personality in FM.

\section{REFERENCES:}

[1] Bazzichi L, Giacomelli C, Consensi A, Giorgi V, Batticciotto A, Di Franco M, Sarzi-Puttini P (2020) One year in review 2020: fibromyalgia. Clin Exp Rheumatol 38 Suppl 123(1):3-8.

[2] Conversano C, Marchi L, Ciacchini R, Carmassi C, Contena B, Bazzichi LM, Gemignani A (2018) Personality Traits in Fibromyalgia (FM): Does FM Personality Exists? A Systematic Review. Clin Pract Epidemiol Ment Health 14:263.

[3] Türkoğlu G, Selvi Y (2020) The relationship between chronotype, sleep disturbance, severity of fibromyalgia, and quality of life in patients with fibromyalgia. Chronobiol Int 37(1):68-81.

[4] Garip Y, Güler T, Bozkurt Tuncer Ö, Önen S (2019) Type D Personality is Associated With Disease Severity and Poor Quality of Life in Turkish Patients With Fibromyalgia Syndrome: A Cross-Sectional Study. Arch Rheumatol 35(1):13-19.

[5] Ablin JN, Zohar AH, Zaraya-Blum R, Buskila D (2016) Distinctive personality profiles of fibromyalgia and chronic fatigue syndrome patients. PeerJ 4:e2421.

Table 1. Binary logistic regression analysis for the evaluation of potential confounders of type $D$ personality in patients with fibromyalgia.

\begin{tabular}{lllll}
\hline & Wald & SE & $\beta(95 \% \mathrm{Cl})$ & $\mathbf{p}$ \\
\hline Education (years) & 4.664 & 0.093 & $0.818(0.682-0.982)$ & 0.031 \\
Occupation duration (years) & 0.116 & 0.037 & $1.013(0.942-1.089)$ & 0.733 \\
Self-esteem scale (D1) & 0.369 & 0.423 & $0.774(0.338-1.771)$ & 0.544 \\
BDI & 8.446 & 0.056 & $1.178(1.055-1.316)$ & 0.004 \\
BAI & 0.789 & 0.032 & $1.029(0.966-1.095)$ & 0.374
\end{tabular}

BDI: Beck Depression Inventory, BAI: Beck Anxiety Inventory, SE: standard error, Cl: confidence interval 